\title{
El existencialismo de Gabriel Marcel. Aspectos del problema de la verdad desde la filosofía concreta
}

\author{
Diego Pereira-Ríos* \\ (iD) https://orcid.org/0000-0002-2202-915X
}

Recibido: 09 de febrero, 2020 - Aceptado: 19 de mayo, 2020

«Hay algo que se llama vivir y algo que se llama existir: yo he escogido existir...»

Gabriel Marcel

Diario Metafísico / 28 de noviembre, 1931

\section{RESUMEN}

En este artículo $^{1}$ se profundiza en la filosofía concreta de Gabriel Marcel, al abordar su aporte específico al problema de la verdad. Se divide en dos partes: la primera donde se expone los conceptos centrales de la filosofía concreta, y la segunda, donde se busca demostrar las reflexiones del autor en torno al problema de la verdad. Marcel centra su atención en el cuerpo como acceso a ella. Propone la verdad como un valor trascendente, buscado por todo ser humano, pero que muchas veces se encuentra impedido de acceder a ella por el avance de la tecnificación de la

\section{Formato de citación según APA}

Pereira-Ríos, D. (2020). El existencialismo de Gabriel Marcel. Aspectos del problema de la verdad desde la filosofía concreta. Revista Espiga, 19 (39), 131-147.

\section{Formato de citación según Chicago-Deusto}

Pereira-Ríos, Diego (2020). «El existencialismo de Gabriel Marcel. Aspectos del problema de la verdad desde la filosofía concreta». Revista Espiga 19, n. 39 (enero-junio, 2020): 131-147.

* Profesor de Filosofía por la Universidad de Montevideo (UM), de Uruguay. Maestrando en Teología Latinoamericana por la Universidad Centroamericana José Simeón Cañas (UCA), de El Salvador. Miembro de la Red Amerindia, Uruguay. Editor en la Revista Ariel, de Uruguay. Miembro de la RED CREA Cómplices Pedagógico, para América Latina. Miembro de «Ágora dos habitantes da Terra», de Brasil. Miembro del Grupo Diocesano de Ecología Integral «San Francisco», de Uruguay. Miembro de la Secretaria Ecuménica, de Brasil. Autor del libro La fuerza transformadora de la esperanza (Montevideo: Nueva Visión Editorial, 2016). Correo: pereira.arje@gmail.com

1. Artículo desarrollado con base en una ponencia presentada por el autor en el IV Congreso Internacional de la Sociedad Filosófica del Uruguay, llevado a cabo del 6 al 9 de junio de 2018, en Montevideo, Uruguay. 
existencia. Para él, entre verdad y libertad hay una conexión importante. Se alcanza ser libre al encontrar la verdad, y se encuentra la verdad al ser libre.

Palabras clave: Libertad, existencia, encarnación, pensamiento, cuerpo.

\section{Introducción}

Se sabe que, en la historia de la filosofía, la búsqueda de la verdad ha pasado por diversas etapas que incluyen crisis, contradicciones, posturas muy desencontradas y pocos casos de coincidencias. Esta búsqueda ha generado innumerables conflictos intelectuales, ideológicos, religiosos y políticos. Por tanto, la verdad como un atributo del ser (el verum escolástico) o como valor dador de sentido o valor por ser descubierto, buscado bajo pretensión de posesión, tiende a ser una meta, un telos hacia donde el ser humano se encamina. Por ello no sería nada espectacular que Gabriel Marcel, como filósofo -o incluso como creyente-, sea también un buscador de esta verdad.

La nota distintiva de este autor es su particular visión acerca de ella: deja de ser un valor únicamente del ser trascendente y, por ello, inaccesible. Lejos de esto, Marcel logra acercarse a esta verdad desde lo inmanente, pero con una profunda y humilde apertura. Alcanza a ser testigo de que es el camino propicio para un real encuentro con la verdad del ser.

La decisión de Marcel de optar por una filosofía concreta, en la cual defiende que solamente desde la existencia humana se puede acceder a un ser que se revela como cercano -aunque de un modo nuevo-, ha llevado a quien escribe este artículo a elegirlo como autor para dicho trabajo. Esta elección se fundamenta en dos fuertes razones: la primera -de orden más bien personal- tiene que ver con que es un segundo intento ${ }^{2}$ que el autor realiza para acercarse a la filosofía de un pensador que no solo ha colmado las expectativas más profundas de la búsqueda filosófica de quien escribe, sino que las ha superado; mucho más que deslumbrarse ante lo que considera un verdadero filósofo, el autor siente un gran llamado por continuar un camino comenzado por Marcel, incorporándolo a su propia vida, a su propio pensar. No logra concebir una filosofía para el siglo XXI que no parta de la misma existencia humana, siempre y cuando se supere la concepción cosificante de la vida humana.

La segunda razón tiene que ver con la actualidad de su pensamiento. Se puede decir que Marcel no solo es un filósofo actual, sino que en este contexto mundial es necesario. Desde el ambiente posmoderno (o transmoderno) en el que se vive en este instante, donde se es testigo de una decadencia, no solo intelectual, sino que también ética y metafísica, y donde la filosofía ha perdido su lugar junto al resto de las humanidades, es de suma importancia la misión y tarea del filósofo que propone Marcel. También, se le puede ver

2. El primer acercamiento a la filosofía de Gabriel Marcel lo tuve hace seis años. El fruto de ese trabajo inspiró mi primer libro La fuerza transformadora de la esperanza (Ed. Nueva Visión, 2016), donde se integra en uno de sus capítulos. 
en la conjunción que logra desde el arte: la música que lo inspira, sus obras de teatro, dan lugar a la necesaria relación entre conocimiento artístico y el pensar filosófico. La filosofía estética tiene en este campo un testimonio por imitar, ya que en su literatura logra expresar los dramas humanos de mejor manera. Por eso, la actualidad de su pensamiento, en un mundo donde la música y la imagen dominan, exige una cierta capacidad de reflexión para darle un cauce acertado.

Marcel no solo ha sido un filósofo asistemático, sino que estuvo férreamente en contra de toda sistematización del pensamiento. Por eso, no se encuentra un tratado acerca de la verdad, como en Tomás de Aquino, o un tratamiento exhaustivo sobre la verdad en alguno u otro trabajo. Marcel es existencialista, parte de la vida, de un pensamiento que se piensa en situación y desde allí reflexiona. Por esta razón, se debe indagar a lo largo de su obra para encontrar algunos de sus escritos en los cuales se detiene a reflexionar acerca de la verdad. Para este trabajo, se utiliza las siguientes obras: Diario metafísico, El misterio del ser, Esbozo de una filosofía concreta, Aproximación al misterio del ser. Posición y aproximaciones concretas al misterio ontológico, Filosofía para un tiempo en crisis, Prolegómenos para una metafísica de la esperanza y Decadencia de la sabiduría. Con la ayuda de la bibliografía secundaria se intenta explicar la filosofía existencialista de Marcel desde sus conceptos centrales, para luego ir hacia el problema de la verdad.

\section{Primera parte. Ideas clave del filosofar concreto}

\section{Un acercamiento al autor}

Gabriel Marcel (1889-1973) fue un filósofo y dramaturgo francés de origen judío, perteneciente a la corriente del existencialismo. Contemporáneo de Sartre, quien fue conocido por ser promotor de un ateísmo atroz, que no solo negaba la existencia de Dios, sino que hacía de cada prójimo un enemigo, a modo de infierno. Frente a ello, Marcel fue capaz de trascender las dificultades de su época y, sin hacer caso omiso de ellas, afrontarlas desde una perspectiva muy diferente. Su capacidad de sobreponerse a sí mismo y a la formación recibida le dio la posibilidad de generar un pensamiento liberado de las cadenas de la filosofía sistemática de sus predecesores y, con ese mismo espíritu, lanzarse en una búsqueda de la existencia humana desde sus posibilidades, no únicamente desde las dificultades.

Sin duda alguna, lo ayudó en esto su pasión por el arte, la música y la literatura, al plasmar en sus obras de teatro las interrogantes más profundas del ser humano de su época. Las inseguridades, los miedos y los sufrimientos se perciben a flor de piel en sus obras; pero siempre en un clima de una búsqueda de algo que se sobreponga a dichas situaciones. Su misma vida está atravesada por este espíritu aventurero, por ello afirmaba que el humano es un homo viator, un ser peregrino, siempre en camino, nunca acabado, sin límites. Este es el motivo de que su filosofía vaya más allá del racionalismo abstracto de Descartes, ampliando la existencia a la posibilidad de conocerse y conocer desde la existencia de los demás seres humanos con quienes convive. No encontrará otro camino para el conocimiento filosófico que el que parte de la vida, con todas sus situaciones, desde las más comunes de la cotidianeidad, hasta las más extremas como la búsqueda de felicidad o la muerte. 
La vocación filosófica de Marcel nace temprano, con la muerte de su madre; la cual, ya desde su infancia, comenzará a provocar su investigación. Al proceder filosófico de Marcel se le puede denominar de un cariz socrático: comienza por preguntas que exigen respuestas, pero que luego le devuelven preguntas. Aunque pareciera un continuo discurrir de un pensamiento hablante, el método de Marcel sostiene un hilo conductor con una gran coherencia interna de nociones que nacen en su juventud. Su dedicación a la filosofía concreta busca llevar paz a las situaciones de desesperación que atraviesan las mujeres y hombres de su época. De ahí que también hará un llamado a los filósofos a meterse dentro de la realidad para, desde ella, lograr lo que él llamó una intuición reflexiva. Pensar, para Marcel, es pensar en situación; y el filósofo es un ser más que busca entenderse para entender, por eso debe reflexionar desde la misma vida, desde las complejidades de le existencia.

\section{Filosofía concreta}

Ante las filosofías que seguían objetivando al ser humano, dividiéndolo en partes como si fuera un simple objeto de la realidad, así mismo, factible de hacer funcionar a voluntad de otros; Marcel opondrá lo que el llamará filosofía concreta. Es claro desde el comienzo, que esta es una respuesta contraria a lo propuesto por el idealismo y el racionalismo: «(...) si la expresión de "filosofía concreta" tiene un sentido, es en primer lugar porque corresponde a un rechazo de principio opuesto a los "ismos", opuesto a una cierta escolarización $»^{3}$. También es claro que resulta en una negación total a cualquier intento de andamiaje sistemático, pues «cada vez veía con más claridad que había algo de absurdo en la pretensión de encapsular al universo en un conjunto de fórmulas más o menos rigurosamente encadenadas $\rangle^{4}$. No estará dispuesto a perderse en razonamientos abstractos, ya que hay que ocuparse en el ser humano. De ahí el carácter profundamente humanístico de su filosofía.

¿Qué significa filosofía concreta o de lo concreto? Esta idea proviene más abarcativamente de la filosofía existencialista y significa, según Garzón, «Tomar las cosas en su concreción, significa verlas unidas a todo aquello que, en la realidad, se encuentra unido a ellas esencialmente $\rangle^{5}$; por ello, es lo contrario a toda abstracción. Ocuparse del ser humano implica estar en la realidad de modo consciente, activo e implicado en ella. Siguiendo a Urabayen, quién se arroje a esta empresa descubrirá que «La gran variedad de la realidad no puede ser recogida en conceptos universalizadores y abstractos. Hay que recuperar la realidad en toda su plenitud y su riqueza de tonalidades y matices» ${ }^{6}$. Incluso, Marcel verá como una traición al filósofo que destine sus esfuerzos a meras abstracciones, lejos de la vida. Por ello la tarea de la filosofía es la dimensión de lo concreto

3. Gabriel Marcel, Esbozo de una filosofía concreta. Obras completas, Tomo II (Madrid: Biblioteca de Autores Cristianos, 2004), 68-69.

4. Ibíd., 69.

5. Juan Garzón Bates, El existencialismo, en Las Humanidades en el Siglo XX. 5: La filosofía (México: Universidad Autónoma de México, 1979), 112.

6. Julia Urabayen, «Las sendas del pensamiento hacia el misterio del ser. La filosofía concreta de Gabriel Marcel», Cuadernos de Anuario Filosófico, n. ${ }^{\circ} 137$ (2001): 22. 
$y$, es ella, quien dirige el pensamiento hacia lo esencial del ser humano: lo personal, lo subjetivo. El punto de partida de la reflexión debe ser el «yo existente» y debe asumir la experiencia vivida a partir de la existencia encarnada. Para Marcel no es tan importante el ¿Hacia dónde se debe dirigir la filosofía? Sino ¿Desde dónde se debe partir? Para saber ¿Hacia dónde orientar el esfuerzo reflexivo? ${ }^{7}$

La filosofía concreta, por tanto, parte de la situación fundamental de reflexionar sobre la condición humana y su existencia cotidiana al formar un todo complejo con la realidad. Dirá Marcel: «En lo que a mí respecta, soy propenso a negar la cualidad filosófica a toda obra en la que no se pueda discernir lo que yo llamaré la mordedura de lo real $»^{8}$. La imagen de mordedura alude a la experiencia sentida en el mismo cuerpo luego de un encuentro con la realidad; la cual, de alguna manera, actúa como condicionante sobre el ser humano. Por tanto, hacer filosofía es hacer el mismo camino de todos los seres humanos y, de alguna manera, hacerse cargo del peso que conlleva un esfuerzo de reflexión que parte desde el mismo interior de las situaciones vitales. Para Davy, en esto se percibe el abismo existente de una filosofía escolástica o una filosofía racionalista, ya que la filosofía concreta parte de un condicionamiento histórico, atravesado por todos los problemas de su época, de lo cual no le es permitido «pasar volando sobre las cosas», sino que se trata «de examinar la situación fundamental en términos concretos»?

\section{El comienzo del pensar: la interrogación}

La objetivación del ser humano como consecuencia del avance de la técnica lleva a Marcel a cuestionarse acerca del lugar que ocupa el ser humano en el universo. Observa que, visto de este modo, el comportamiento humano: «(...) llega así, inevitablemente, a lo que llamaría una pragmatización general del hombre y de las relaciones humanas...» ${ }^{10}$. Por eso, surgirá, muy fuertemente, la necesidad de interrogarse, de interpelarse, como profunda necesidad de ver allí, en medio de esa situación concreta en la que se encuentra, el alcance de tales preguntas. Esto lo lleva a un análisis de la pregunta: «Sin embargo, vamos a reflexionar sobre la naturaleza de esta interrogación y sobre las condiciones en las que se emprende $\rangle^{11}$. Muy contrariamente a un experto, que podría llegar a plantearse preguntas del orden trascendente o acerca del destino final del ser humano, Marcel parte desde un lugar primario: «¿Sobre qué puedo interrogarme? ¿Sobre lo que pienso?» ${ }^{12}$.

Marcel conoce muy bien el riesgo de perderse en pensamientos que no lo llevarán hacia donde quiere ir. Su filosofía concreta es a la vez una metafísica y, como tal, intenta superar el ámbito de lo comprensible a primera vista. Frente a la clásica noción de ente y ser, Marcel se interroga desde un más acá pensable, «¿Qué es el ser con relación a las apariencias? $\gg^{13}$, más aún, intenta no caer en preguntas que no podrá responder. Frente

7. Ibíd., 124.

8. Marcel, Esbozo de una filosofía...,73.

9. Marie-Madeleine Davy, Un filósofo itinerante: Gabriel Marcel (Madrid: Gredos, 1963), 240.

10. Gabriel, Marcel, Decadencia de la sabiduría (Buenos Aires: Emecé, 1955), 41.

11. Gabriel, Marcel, Filosofía para un tiempo de crisis (Madrid: Guadarrama, 1971), 78.

12. Ibíd., 81.

13. Ibíd. 
a la pregunta por el acto de ser se pregunta: «¿Qué es actuar? ¿Qué es padecer?» ${ }^{14}$. Desarrolla, poco a poco, su método fenomenológico como camino de acceso al ser, que se deja captar no solo desde la dimensión racional, sino sobre todo en su modo de actuar. De alguna manera, también cuestionará si el alcance logrado por la filosofía acerca del ser no ha sido un juego de palabras, un puro flatus vocis. Difícilmente, las conceptualizaciones logradas por una filosofía tomista acerca de las cuestiones del ser incidan en las personas comunes.

Se debe captar la naturaleza de la interrogación: no es una simple curiosidad, sino una inquietud profunda. La primera es exterior, periférica, lo propio de un pensamiento científico situado desde afuera ante el objeto que investiga. La inquietud filosófica tiene otro interés: tiene este «in» que indica desde donde nace: del interior del ser humano, inmerso en una situación que lo incluye, que lo afecta y, por tanto, lo condiciona. Para Davy, este pensamiento interrogativo es una necesidad de orden metafísico: es una inquietud a modo de apetito insaciable: «la inquietud, según Marcel, tiene relación con el centro inmóvil que va buscando y que quiere abarcar a toda costa» ${ }^{15}$. La pregunta filosófica es ante todo un autocuestionamiento, un colocarse dentro del problema que le afecta a uno para, desde dentro, intentar responder al saber que se pregunta del mismo modo en el cual cualquier otra persona que esté en dicha situación se pueda preguntar.

De este modo, con preguntas y respuestas que nunca cierran del todo la interrogante, sino que, por lo contrario, abren a nuevas preguntas, Marcel procederá de modo dialéctico en su propia búsqueda filosófica. Preguntar es un intento de responder a una situación de indeterminación de la misma vida, que exige una palabra, una explicación que genera una tensión entre lo que no se logra comprender, pero se experimenta. Por ello las situaciones concretas como el amor, el sufrimiento, la desesperación, la muerte, son situaciones desde donde parten las preguntas; siempre con la particularidad del sujeto: el alcance de una respuesta para determinada persona no debe por qué satisfacer la necesidad de otro sujeto. Aquí es importante entender que el ser humano no es fabricado en serie; Marcel proclamará la defensa de la particularidad humana con todo el peso que tiene su subjetividad. Por eso la sensación de un continuo vacío en las respuestas es posible: «Después de cada pareja de preguntas y respuestas, se encuentra uno frente a un vacío; la progresión exige llenar ese vacío. Y la pregunta se plantea de nuevo, se examina momentáneamente, reanudada otra vez conforme a una dimensión nueva» ${ }^{16}$.

\section{Pensamiento pensante}

La exigencia del pensar filosófico debe trascender todo intelectualismo posible, esto para no caer en un engañoso solipsismo, por esto se hace necesario el estar parado en la realidad de un modo comprometido con los demás. Por ello se parte de una situación metafísica: «(...) este acto metafísico que me liga a un ser -al ser- presenta siempre una cara que corresponde a la actividad del pensamiento tomado como edificación o como

\footnotetext{
14. Ibíd., 78 .

15. Davy, Un filósofo..., 224.

16. Ibíd., 226 .
} 
reconocimiento» ${ }^{17}$. Este pensamiento es un continuo pensar a partir de lo concreto de la existencia humana: «Una filosofía concreta es una filosofía del pensamiento pensante y sólo puede crearse mediante una especie de peligrosa y continua acrobacia» ${ }^{18}$. De ahí su continua actividad como incansable esfuerzo reflexivo en búsqueda de una verdad que no intentará nunca abarcarlo todo, descifrarlo todo; pero que, sin embargo, no puede dejar de renunciar a ello.

Desde la diferencia que hará Marcel entre problema y misterio, surgen nuevas interrogantes. Para Marcel: ${ }^{19}$

Distinción entre lo misterioso y lo problemático. El problema es algo que se encuentra, que obstaculiza el camino. Se halla enteramente ante mí. En cambio, el misterio es algo en lo que me hallo comprometido, a cuya esencia pertenece, por consiguiente, el no estar enteramente ante mí. Es como si en esta zona la distinción entre en mí y ante mí perdiera significación.

Por tanto, a la hora de pensar lo que no puede ser captado -el mismo pensar es un misterio-, Marcel dirá: «Mas hay que reconocer que es extremadamente difícil. Lo que yo veo es que el acto de pensar es irrepresentable y debe aprehenderse como tal» ${ }^{20}$.

De este modo Marcel se percibe a sí mismo como inmerso en un pensamiento siempre en acto, por eso pensante, pero del cual no puede captarse sino en el mismo acto del pensar: «En efecto, la actividad filosófica central no se definía para mí como una construcción, sino más bien como una profundización» ${ }^{21}$. Pensar es una aventura a la cual se embarca toda la persona desde su ser más íntimo, pero no implica de todos modos una total comprensión de sí. De esta manera Marcel se cuestiona: «Ayer tuve ocasión de profundizar la distinción entre pensar y comprender. ¿No hay, sin embargo, algo falaz en la idea de un pensamiento que no fuese comprehensión? Pensar, en este caso, ¿no sería creer que se piensa? No se comprende sino en función de lo que se es» ${ }^{22}$. El punto de partida del pensar es la singularidad de cada sujeto y su acto mismo de pensar.

Hay en todo ello un rasgo de una gran humildad por parte de Marcel. Un pensamiento comprometido, interpela el ser de quien lo piensa y, por ello, le exige seguir pensando, de examinar el modo en el que piensa dentro del mismo pensar universal: «El punto de partida de una filosofía auténtica -y entiendo por auténtica una filosofía que es la experiencia transmutada en pensamiento- es sin embargo el reconocimiento, lo más lúcido posible, de esta situación paradójica que no sólo es la mía, si no que me hace yo» ${ }^{23}$. Los filósofos no son los creadores de algo totalmente nuevo ni tampoco hacen descubrimientos fantásticos. Esto exige la claridad intelectual de reconocer sus limitaciones ante la realidad compartida con los demás seres, por cuanto su esfuerzo y tarea es parte del

17. Gabriel Marcel, Diario metafísico (Madrid: Guadarrama, 1969), 41.

18. Marcel, Esbozo de una filosofía...,19.

19. Marcel, Diario metafísico..., 124.

20. Marcel, Ibíd...., 156.

21. Marcel, Esbozo de una filosofía..., 20.

22. Marcel, Diario metafísico..., 101.

23. Marcel, Esbozo de una filosofía..., 33. 
todo. Pensar, es pensarse desde otros, con otros y para otros; como pensador de la experiencia, es forjado por ella. De ahí el profundo respeto y humildad de una pensamiento que se piensa a sí mismo siempre en camino.

\section{Responsabilidad del filósofo}

De todo lo dicho hasta aquí, surge la gran responsabilidad de aquellos que se llamen a sí mismos filósofos. Contra los idealistas, Marcel había recuperado el lugar de la existencia a la hora de pensar la realidad, por ello le devuelve el estatus metafísico que le corresponde. Por eso, el filósofo deberá contrarrestar el dualismo provocado por Descartes, quien sometió la existencia al ámbito de la razón, partiendo al ser humano en dos ámbitos distintos y difíciles de reconciliar. El pensar, como previo al existir, dictaminó un camino en la historia de la filosofía que, cada vez más, fue degradando la existencia humana, colocándola en un lugar de inferioridad metafísica: «(...) debo aclarar que de ninguna forma veo en ella el sujeto ideal del conocimiento. De forma general el cogito entendido a la manera idealista -no me pronunciaré con respecto a si puede o no ser tomado en otra acepción- no se me muestra como punto de partida de una metafísica posible» ${ }^{24}$.

El camino del filósofo - para Marcel- comienza con una llamada; por tanto es una vocación a la cual no puede negarse. Es el comienzo de un camino desconocido, pero que irresistiblemente lo impulsa a recorrer en la defensa del ser humano en todas sus dimensiones, partiendo siempre de la realidad en la cual se encuentra. «El filósofo, hoy como en cualquier época, se encuentra en un cierta situación histórica de la que es muy poco verosímil que pueda abstraerse realmente: sólo siendo víctima de una ficción se imagina que puede hacer el vacío en sí y en torno suyo» ${ }^{25}$. Es la realidad concreta en el ámbito del filosofar que incluye el espacio y el tiempo donde se desarrolla la vida humana. Dice Davy: «Para Marcel, el pensamiento es una reflexión que puede brotar de tal encuentro o de cual conversación, hasta del más modesto incidente del vivir cotidiano, y que, sin embargo, no desmerece en nada por el humilde contexto en que se encuentre» ${ }^{26}$.

El filósofo debe ser un hombre y una mujer de su tiempo, vinculado a la porción de humanidad que le toque en suerte, pero con una mirada más amplia: a toda la humanidad. Esto no puede ser algo ideal, abstracto, sino que el compromiso debe ser personal, en relación con los demás y como gran meta: la verdad. Al preguntarse ¿Ante quién es responsable el filósofo?, dirá Marcel que «el filósofo es responsable ante la sociedad» ${ }^{27}$, por lo que le exige una verdadera ascesis ante los influjos que puedan torcer su camino. Si se dejara afectar por presiones políticas o religiosas, o si se dejara seducir por la búsqueda del éxito o el poder «infringe de inmediato una de las condiciones de la búsqueda filosófica que debe considerarse como imprescindible. Esta condición es la autonomía» ${ }^{28}$. Pero esta autonomía debe ejercerla siempre como servicio al resto de los hombres y mujeres,

24. Marcel, Esbozo de una filosofía..., 33.

25. Gabriel Marcel, Aproximación al misterio del ser. Posición y aproximaciones concretas al misterio ontológico (Madrid: Encuentro, 1987), 79.

26. Davy, Un filósofo..., 233.

27. Marcel, Filosofía para un tiempo..., 45.

28. Ibíd. 
a quien se debe en completa disponibilidad. En esta disponibilidad está la verdad del filósofo.

\section{Segunda parte. De la participación corporal como medio, a la verdad}

\section{Cuerpo y realidad como encuentro con la verdad}

El sujeto está siempre metido en la realidad de la cual no puede hacer abstracción sin ser afectado por ella. Marcel se cuestiona acerca de la posibilidad de pensarse dentro de la realidad y, aún más, se cuestiona si en realidad puede pensar la realidad de forma objetiva: «¿La realidad no me resulta impenetrable por hallarme comprometido en ella?»»29. Pero también, como buscador de la verdad, necesita alcanzar la posibilidad de que en la realidad exista una verdad que se pueda revelar a todo ser humano. Se podría decir que esta realidad se compone de un espacio y tiempo como coordenadas similares para todos, pero no logra una homogenización debido a que las experiencias personales de cada ser son totalmente distintas, condicionando así su conciencia que intenta orientarse a la verdad.

En este sentido, es imposible proseguir en un camino de búsqueda de una verdad universal para todos, pues «En el fondo, el problema metafísico de la verdad, ¿no consiste en saber si no habría en la verdad algo que se niega a prestarse a esa especie de esclavizamiento a que queremos reducirla?» ${ }^{30}$. La pretensión de una verdad universal y absoluta queda dentro del ámbito de la sospecha de una búsqueda egoísta de un haber, de una posesión de la verdad. Esta marca distintiva del ser humano, de necesitar conocer para poseer, ha provocado grandes desastres en la historia. Marcel no negará que es posible una verdad común a todos, pero insistirá en que la realidad de cada ser humano revela que también cada uno puede alcanzar su propia verdad. Dirá Marcel: «En otros términos, la verdad se distingue de la realidad en la medida que es sólo un aspecto, en que es unilateral, mientras que la realidad es por esencia omnicomprensiva ${ }^{31}$.

Es justamente en la realidad de la existencia humana donde se hace posible un encuentro con la verdad, pero sin pretensiones universalistas; se debe partir de la existencia concreta de cada ser ¿Cuál es el dato esencial de la condición existencial? ¿Qué le hace a alguien tomar conciencia de su existencialidad? Ese dato es el propio cuerpo, mi cuerpo. Es él quien se comunica con la realidad que rodea a una persona y que la hace vivir las experiencias propias que le condicionan: «(...) mi cuerpo es el punto de partida con relación al cual se plantean para mí los existentes y, añadiría, se establece la demarcación entre existencia y no existencia $»^{32}$. Es únicamente desde la corporalidad que se puede acceder a la verdad, con ese matiz unilateral del que habla Marcel, ya que se debe percibir las limitaciones físicas y metafísicas. Según Davy, el cuerpo es el punto de inflexión de sus posibilidades, pero que no es un simple instrumento, sino «un mediador absoluto, causa y garantía de mi presencia en el mundo, indivisiblemente ${ }^{33}$.

\footnotetext{
29. Marcel, Diario metafísico..., 27.

30. Ibíd.

31. Gabriel, Marcel, El Misterio del ser (Buenos Aires: Sudamericana, 1953), 65.

32. Marcel, Esbozo de una filosofía..., 33.

33. Davy, Un filósofo..., 241.
} 
El descubrimiento de la corporalidad revela que se está en el mundo como seres encarnados. La encarnación es entonces el dato metafísico revelador de una verdad personal dentro del inmenso espectro de la realidad. Pero no basta decir «soy mi cuerpo», pues se corre el riesgo de ser reducido a él. Por lo tanto, no posee un cuerpo a modo de quien posee un objeto. Este es al alcance de una reflexión primaria. Para Kaufmann es por eso que «esta posesividad es ante todo una experiencia que más que ser descrita, debe ser aludida o evocada... este misterioso lazo se presenta de un modo tan radical...» ${ }^{34}$. Dirá Marcel: «Todo lo que puedo considerar es que mi experiencia implica para mí la posibilidad de comportarme de maneras a la vez muy precisas y muy variadas con respecto a mi cuerpo... $»^{35}$. A partir del cuerpo se descubre la posibilidad existencial de encaminarse hacia cierta verdad que tendrá relación directa con ese cuerpo. Existe -con el cuerpouna relación necesaria, un lazo de unión consigo mismo y como adherencia de su propio ser al mundo. Este es el camino propio del encuentro con la verdad.

\section{La encarnación como participación en la verdad}

La encarnación será entonces la posibilidad reveladora de un ser existente para sí, pero que también implica un ser para los otros. Existir contiene el prefijo «ex» que viene significando un salirse hacia, estar orientado hacia afuera. Esto implica que todo ser es un ser abierto o un ser-para los demás, lo que implica una superación de la afirmación de la propia existencia. «Yo existo: esto quiere decir que poseo algo para darme a conocer o reconocer, ya sea por otra persona, ya sea por mí mismo en tanto que asigno para mí una alteridad ficticia.... ${ }^{36}$. La conciencia de la propia existencia implica la existencia de los demás que se perciben a sí mismos de la misma manera. Decir que existo, o que yo existo, implica una apuesta a una unidad compleja del ser mismo que se percibe como ser, como otro yo soy. Dirá Marcel: «A mí me parece que el yo soy se presenta como un todo indivisible $»^{37}$. Pensar en mí, es pensarme siendo yo, no es primero el pensar de Descartes donde el existir queda en segundo lugar. Al pensar lo hago siendo.

La filosofía de la existencia tiene que ver con una aceptación del carácter misterioso que posee, por ello «no se puede disociar realmente: Existencia; Conciencia de sí como existente; conciencia de sí como ligado a un cuerpo, como encarnado» ${ }^{38}$. Desde estas posibilidades existenciales, es que el sujeto puede alcanzar una verdad en contacto con los demás sujetos, en un intercambio intersubjetivo que supone dicha encarnación. Este intercambio se da por una participación que implica la reflexión segunda para superar la objetividad en la que puede caer el pensar desde el cuerpo. Afirma Gallardo que «Esta participación significa por un lado, un trascender del yo hacia la instancia suprema, pero también un trascender hacia los demás yoes y un trascender hacia el propio cuerpo. La existencia no es un recinto cerrado sino comunicación con lo otro de nuestro cuerpo» ${ }^{39}$.

34. Sebastián Kaufmann, «La metafísica de la existencia humana de Gabriel Marcel», Veritas, n. ${ }^{\circ} 28$ (2013): 75.

35. Marcel, El Misterio del..., 97.

36. Marcel, Esbozo de una filosofia..., 23.

37. Marcel, Aproximación al misterio..., 34.

38. Marcel, Diario metafísico..., 13.

39. Antonio Gallardo, «Apología del cuerpo desde la mirada de Gabriel Marcel», Thémata, n. ${ }^{\circ} 33$ (2004): 133. 
Participar tiene que ver con ser parte integrante de un todo en el cual hay lugar para el yo personal unido con los demás sujetos que actúan e interactúan conmigo. Por eso, mi existencia a partir de la participación, nunca la puedo pensar separada de los demás: «(...) esta participación que constituye mi presencia en el mundo sólo puedo afirmarla, encontrarla, restaurarla, resistiendo a la tentación de negarla, es decir, de plantearla como entidad separada $\rangle^{40}$. Es desde esta participación que se hace posible un pensar unificado a la existencia, formada a partir de una reflexión metafísica que logre acceder al ser que está unido a otro cuerpo que se presenta ante mí. Es el peso metafísico de la presencia «como aquello de que no dispongo en ningún grado, aquello que no tengo» ${ }^{41}$, contra toda intención de tener - poseer-al otro que está ante mí, solo queda el espacio de reconocimiento que es ante mí, y yo soy ante él. La relación posible es de mutua admiración, nunca posesión.

Por eso, en la relación que surge desde el encuentro con el otro, hay una superación de una captación cognoscitiva donde no puede haber una perfecta conceptualización del otro. No puede más que haber un posible nombramiento del otro, pues al nombrarlo, al llamarlo por su nombre, se hace partícipe de mi conocimiento de sí y, donde también, hay un reconocimiento por parte suya. Pero este llamado exige su presencia ante mí. Debe haber, en todo esto, una renuncia a toda soberbia, es un estar en posesión de un saber, ya que el otro es un misterio que nunca podré conocer ni abarcar. La atención, como meditación serena y humilde ante el otro y ante la realidad, es la posibilidad de una reflexión que no cosifique al otro, permitiéndole ser él mismo en su verdad. En este sentido «El filósofo no tiene por qué ejercitar su pensamiento en una verdad que juzgue personalísima, pues toda verdad está dotada de un carácter de impersonalidad: ahí es donde reside su valor» ${ }^{42}$.

\section{Verdad como valor trascendente}

En un primer acercamiento a la filosofía existencialista de Marcel, pareciera que la verdad quedaría reducida a un alcance inmanente, por lo que estaría por fuera toda pretensión de una verdad absoluta. Esto, quizá sea más bien el error de no lograr salir del plano objetivizante de la realidad; según Presas, Marcel diría «que la verdad hacia la cual aspira la búsqueda filosófica, es por esencia imposeíble: no puede ser considerada o tratada, de ninguna manera, como un tener» ${ }^{43}$. Esto tiene que ver con una nueva interpretación de la verdad: «(...) desde el momento en que se introduce la palabra participación nos vemos llevados a sustituir el término verdad por el término ser (...)» $\rangle^{44}$. Pero de alguna manera, en su progreso reflexivo, Marcel aclara: «Hoy declararía, más bien, que el ser y la verdad son idénticos, pero con la condición de señalar, como lo he hecho más arriba, la inconmensurabilidad de la Verdad con relación a las verdades finitas... $\rangle^{45}$.

\footnotetext{
40. Marcel, Esbozo de una filosofía..., 29.

41. Marcel, Diario metafísico..., 13.

42. Marcel, Diario metafísico..., 228.

43. Mario Presas, Biblioteca de pensamiento esencial. G. Marcel (Buenos Aires: Centro Editor de América Latina, 1967), 37.

44. Ibíd.

45. Ibíd., 38 .
} 
Para Presas, Marcel está proponiendo una verdad que se revela fenomenológicamente en las verdades particulares, ya que «La verdad, en el sentido filosófico de la palabra, es inconmensurable con las distintas verdades particulares $\rangle^{46}$. Pero advierte Marcel, que no debe ser confundida esta verdad con las conclusiones del sabio en sus pacientes investigaciones ni, tampoco, puede ser confundida con el enunciado que ella resume. En sí misma «la verdad sólo puede ser objeto de alusión (...) en una situación determinada en que la verdad se nos aparece más allá de toda definición posible» ${ }^{47}$. Por eso no será aceptada cualquier definición de verdad a modo personal que suponga ser impuesta a otros, porque «pertenece a la esencia de las verdades particulares el ser despersonalizadas, el pretender una validez intrínseca» ${ }^{48}$.

Así resulta necesario que Marcel rescate la verdad como valor trascendente. Afirma que la verdad supone una estructura que se sostiene sobre bases espacio-temporales que desbordan la conciencia directa del sujeto y no le permiten una exacta captación de la verdad. Todas estas aclaraciones parten de que «Las dificultades que se agregan a la noción de verdad en gran parte se deben a la confusión en que nos encontramos al tratar de definir este hecho esencial $»^{49}$. Con esto se da una pista a favor: como todo hecho, se puede situar y, en todo caso, introduce la cuestión de que sí se puede estar en la verdad. «Decir que alguien está en la verdad o en el error supone algo así como si la verdad o el error consistiesen en una atmósfera en la cual el espíritu, y no el cuerpo, quedase por así decirlo, inmerso $»^{50}$. En este sentido, la reflexión filosófica y el valor de la verdad son inseparables para acceder a ciertas verdades.

La búsqueda de la verdad como valor trascendente tiene que ver con colocarse en el lugar de quien quiere consagrarse a ella en un camino hacia la búsqueda de su propia verdad. «Si consagro mi vida a servir una causa en la que está en 'juego' un valor supremo, al mismo tiempo mi vida recibe de ese valor una consagración que la sustrae a las vicisitudes históricas» ${ }^{51}$. La vida filosófica implica una entrega profunda a la tarea del pensar, en la cual se va conformando la misma vida en función de esa tarea. Por lo que queda claro que lo que debe ser buscado es una «sobrevaloración del ser mismo, que puede traducirse y se traduce con la mayor frecuencia por una absoluta posesión de sí, una serenidad en cierto modo sobrenatural $»^{52}$. Por esto, la verdad no se dejará poseer, no se podrá retener, pues trasciende, pero a su vez, hace necesaria la presencia en cuerpo y espíritu para que se dé ese encuentro.

\section{Relación entre verdad y libertad}

Si la verdad puede ser vista como una potencia efectiva, deberá arrojar luz ante la situación a la que se enfrenta todo ser humano: la necesidad de libertad. Ante el avance de la técnica, Marcel se cuestiona acerca de la libertad como otro de los valores trascendentes

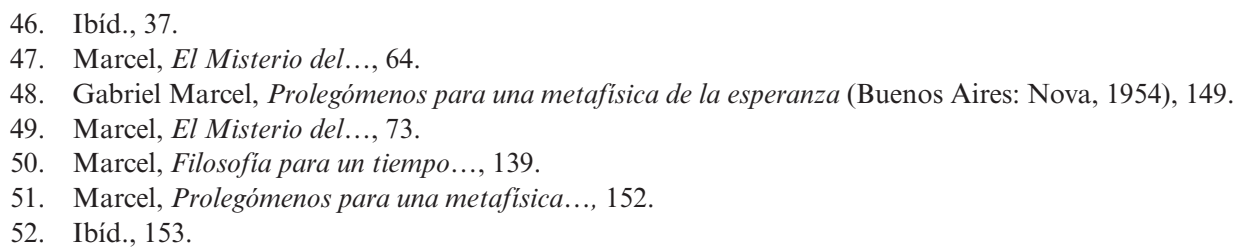


y, al hacerlo, percibe la pérdida de libertad del sujeto, que es cada vez menos respetado. Por eso, se ve obligado a buscar una necesaria relación entre verdad y libertad, y propone cuestionar si «matar en un ser el sentido de la verdad supone atacar a su autorrespeto» ${ }^{53}$. Sin duda que el sometimiento del ser humano a un trato cosificante y objetivizante tiene como consecuencia la pérdida de sentido de ese ser concreto; quien no es identificado más allá de su función social, queda anulado por fuera de sus deseos y metas interiores. Con ello, desde ese mismo prejuicio social, se lo limita en su libertad de ser quien realmente es o desea llegar a ser.

Al aclarar dos aspectos de la libertad, dirá Marcel: «Negativamente, la libertad se define, por tanto, como la ausencia de todo lo que se aparezca como una alienación» ${ }^{54}$; mientras en su forma positiva: "Actúo libremente cuando los motivos de mi acto se encuentran en línea de lo que puedo legítimamente considerar como los rasgos estructurales de mi personalidad $\rangle^{55}$. Dicho de un modo más sencillo, soy yo mismo cuando puedo estar en contacto con otros en comunidad, lejos de todo apartamiento espacial, temporal, psicológico. Y por lo tanto, en el reconocimiento mutuo de seres que se respetan, puedo darme a conocer como soy, con mis propias características y originalidades. Esto de alguna manera implica tomar una actitud existencial ante la vida, pues «este valor consiste ante todo en mirar a la verdad cara a cara y en oponerse al engaño bajo todas sus formas» ${ }^{56}$.

Si se afirma que el ser humano es un misterio, no se puede dejar de reconocer la injusticia en la cual viven millones de hombres y mujeres, sometidos a toda clase de esclavitudes, viviendo en un error forjado por la maldad de otros que hacen que pierdan su sentido de vida. Por eso, es imprescindible un pensar que se acerque a la verdad $-\mathrm{O}$ que sea tocado por ella- para hacer posible la libertad. Afirma Aguilar: «Filosofar es en este sentido, expresar el ser presente que se haya inexpresado. Esta expresión emana de nuestra libertad: al ser sólo se le puede declarar libremente. La presencia indudable del ser pide nuestro libre consentimiento» ${ }^{57}$. Por eso es necesaria una reflexión que vincule intrínsecamente: verdad, libertad, justicia; y, al percibir que no se dan las condiciones existenciales para que se desarrollen, debe denunciarlas.

Dirá Marcel que la verdad es como una luz: «La verdad puede deslumbrar y herir como la luz cuando se mira de frente, y aquel que la ignora por su propia voluntad se ciega deliberadamente... $»^{58}$. Al querer acceder a la verdad desde el esfuerzo únicamente racional, se corre el peligro de ser cegado totalmente por la luz de la verdad o, incluso, seguir hacia las espesas penumbras del error. Aguilar dice que, por lo contrario, la luz de la verdad puede iluminar el camino de acceso al ser, en comunión con otros que comparten las mismas búsquedas y de las relaciones que puedan «crear un vínculo fraterno entre ellas, habla de la 'luz' que los une» ${ }^{59}$. Si el ser humano camina en pos de una verdad a la que puede acceder con otros, sin duda podrá ser más libre y construir una sociedad

\footnotetext{
53. Marcel, Filosofia para un tiempo..., 128.

54. Ibíd., 130.

55. Ibíd., 131

56. Ibíd., 133

57. Luis Aguilar, «La verdad que educa al hombre. Bajo dos miradas filosóficas: María Zambrano y Gabriel Marcel», Teoría y Praxis, n. ${ }^{\circ} 10$ (2007): 101

58. Marcel, El Misterio del..., 68.

59. Aguilar, «La verdad que educa», 103.
} 
más justa para todos: «En la ciudad ideal, como la vislumbramos, deriva justamente de la existencia de esta luz que es la verdad $»^{60}$.

\section{Conclusión: El desarrollo del espíritu de verdad}

Marcel no ofrecerá, en ningún momento, una definición de verdad, pues esto iría en contra de su postura filosófica. La verdad no puede ser expresada en conceptos abarcativos porque la encerrarían, limitándola. Esto no niega la posibilidad a su acceso, sino que prefiere provocar una cierta actitud vital ante ella: «Por mi cuenta preferiría hablar aquí del espíritu de verdad» ${ }^{61}$. Desde la filosofía concreta solamente se puede proceder al modo descriptivo-fenomenológico para acercarse a tal espíritu de verdad. De modo que se puede reconocer, en aquellas personas que se considera no lo poseen, una cierta capacidad de ser desarrollado si así se dispusieran, ya que lo poseen, aunque en ausencia: «El espíritu de verdad puede, además, habitar totalmente en un ser que, en el curso de su existencia, no ha tenido la ocasión o la posibilidad de reconocer sino un número muy pequeño de verdades particulares, y para quien esas verdades nunca se han formulado en términos que permitan transmitirlas o a fortiori enseñarlas ${ }^{62}$. Esto exige un examen de vida de cada uno para descubrir ciertas verdades que le son propias a su existencia, las cuales, una vez captadas y aprendidas, pueden ser enseñadas.

Desde esto, se entiende que todos los sujetos pueden adquirir cierta capacidad de acercamiento a la verdad, relacionando sus verdades particulares con el todo existente. «Lo que depende de nosotros es, en suma, disponernos favorablemente con relación a la gracia posible» ${ }^{63}$. El término "gracia», Marcel lo propone también como don, como regalo recibido a quien se disponga. Aquí aparece uno de los rasgos de un espíritu de verdad: la disponibilidad. «El ser disponible es aquel ser capaz de estar todo íntegro conmigo cuando yo lo necesito» ${ }^{64}$ y que se da a sí mismo sin pensar en un retribuir de nada; sin embargo, recibe como don el propio ser. Es estar en un estado de receptividad en el cual otro ser me hace partícipe de sí, donde mi ser se ve enriquecido. Pero ¿Qué es recibir? «Recibir es admitir o acoger en su casa a alguien de afuera». Se trata entonces de que «recibir es introducir al otro, al extranjero, en esa zona cualificada y admitirle en cierto modo su participación en ella» ${ }^{65}$. Estar disponible para recibir la verdad implica abrirse para que el ser de la verdad haga partícipe a alguien de ella y, desde ella, es que ese alguien se comprenderá mejor a sí mismo.

Esta disponibilidad también aparece bajo otra cualidad: «El espíritu de verdad lleva otro nombre, más revelador aún; es también espíritu de fidelidad» ${ }^{66}$; es aquí donde aparecen los rasgos más claros de una filosofía concreta pues ¿Dónde se hace experiencia de fidelidad? En la amistad, en el amor, en el sufrimiento. De aquí que Marcel incluso

\footnotetext{
60. Marcel, El Misterio del..., 79.

61. Marcel, Prolegómenos para una metafísica..., 150.

62. Ibíd.

63. Ibíd., 151.

64. Marcel, Aproximación al misterio..., 72.

65. Marcel, Esbozo de una filosofía..., 34.

66. Marcel, Aproximación al misterio..., 67.
} 
hablará de una fidelidad creadora: «La fidelidad creadora consiste en mantenerse activamente en estado de permeabilidad; y aquí vemos operarse una especie de intercambio misterioso entre el acto libre y el don por el cual es correspondido» ${ }^{67}$. Es justamente en esta fidelidad donde el ser puede ser realmente libre. Fidelidad es aceptar los descubrimientos que se van haciendo de nosotros mismos y, a su vez, al descubrir las verdades de otros, mantenerse en esa actitud de dejarse afectar sin querer cambiar la verdad descubierta. Esa verdad es libertad. Quien logra estar siempre en situación de entrega continua hacia los otros descubre que es dando cuando más se recibe, allí radica su libertad: no quiere poseer nada, porque no le interesa. Incluso ni siquiera él mismo se pertenece y en ese reconocimiento de desprendimiento de todo, ejerce su libertad.

Ante la imposibilidad de conceptualizar la verdad, de retenerla ante formulaciones lingüísticas o matemáticas, Marcel introduce un plano metafísico donde la verdad se hace vida desde la existencia concreta de cada persona; por eso habla de un espíritu de verdad que se experimenta en las situaciones cotidianas de lo humano. Describe situaciones humanas donde se juega esa verdad; dice Marcel: «(...) hay una manera de escuchar que es una manera de dar; hay otra manera de escuchar que es una manera de rehusar, de rehusarse: el don material, la acción visible, no es necesariamente testimonio de presencia...La presencia es algo que se revela inmediatamente e irrecusablemente en una mirada, en una sonrisa, en un acento, en un apretón de manos $\rangle^{68}$. El espíritu de verdad, que es de fidelidad a su vez, implica un compromiso con el otro, donde alguien se da por entero, por puro amor y entrega incondicional. Por ello la caridad como presencia, como disponibilidad absoluta, es el acto más grande de entrega libre del propio ser por causa de otros seres.

Muchas veces, por caridad, entregar la vida implicará perderla para que otros encuentren la suya; por ello, también «El espíritu de verdad se identifica aquí con el espíritu de fidelidad y de amor» ${ }^{69}$. Con esta afirmación, Marcel se remonta al inicio de los tiempos para recuperar la misma fuente de la filosofía como amor a la sabiduría. Buscar la verdad, como valor revelador de la existente, supone una actitud apasionada por la vida, por el ser humano. Por eso, no se hallará esa verdad solamente desde el pensamiento, sino que el pensamiento parte de la existencia, dentro de la cual, se es un ser encarnado que ama y sufre, que confía y arriesga. En ese camino se encuentran verdades reveladas en actitud de apertura y se descubrirá la verdad de otros sujetos que también la reciben. Por eso, el espíritu de verdad se podría identificar con el espíritu de amor, como el valor más grande dentro de la existencia humana. Amar sería entonces el camino para vivir una vida verdadera, una vida donde se puede dar a conocer la verdad propia en entrega y fidelidad a alguien concreto, a un ser concreto. La verdad como amor, quizá sea una clave para comprender la filosofía existencialista propuesta por Marcel.

67. Ibíd., 68 .

68. Ibíd., 71-72.

69. Ibíd., 72 . 


\title{
ABSTRACT
}

\section{Gabriel Marcel's existentialism. Aspects of the problem of truth from the perspective of the concrete philosophy}

\begin{abstract}
This article deepens on Gabriel Marcel's concrete philosophy, approaching his specific contribution to the problem of truth. This article is divided in two parts: the first part develops the central concepts of the concrete philosophy, and the second one intends to prove the author's reflections on the problem of truth. Marcel focuses his attention to the body to access the truth and he proposes it as a transcendent value, sought by all human beings, but many times impeded to be accessed because of the technification of the existence. For Marcel, there is an important connection between truth and freedom; achieving freedom is possible when finding the truth and truth is found when being free.
\end{abstract}

Key words: Freedom, existence, incarnation, thoughts, body.

\section{RÉSUMÉ}

\section{L'existentialisme de Gabriel Marcel. Aspects du problème de la vérité dès la philosophie concrète}

Cet article approfondit dans la philosophie concrète de Gabriel Marcel, en abordant son apport spécifique au problème de la vérité. L'article se divise en deux parties: la première expose les concepts centraux de la philosophie concrète; et la deuxième, vise à démontrer les réflexions de l'auteur autour du problème de la vérité. Marcel met l'accent dans le corps comme accès à la vérité et il la propose comme une valeur transcendante, recherchée par l'être humain. Cependant, plusieurs fois, il ne la peut pas accéder à cause de la technicisation de l'existence. Pour lui, entre la vérité et la liberté il y a une connexion importante; l'être humain atteint la liberté quand il rencontre la vérité, et il trouve la vérité quand il devient libre.

Mots-clés: Liberté, existence, incarnation, pensée, corps.

\section{Fuentes consultadas}

\section{Obras de Gabriel Marcel}

Marcel, Gabriel. El Misterio del ser (Trad. M. Eugenia Valentié). Buenos Aires: Sudamericana, 1953

Prolegómenos para una metafísica de la esperanza (Trad. E. Zanetti-V. P. Quintero). Buenos Aires: Nova, 1954.

Decadencia de la sabiduría (Trad. B. Guido). Buenos Aires: Emecé, 1955

Diario metafísico (Trad. F. del Hoyo). Madrid: Guadarrama, 1969.

Filosofía para un tiempo de crisis (Trad. F. García-P. Buendia). Madrid: Guadarrama, 1971.

Aproximación al misterio del ser. Posición y aproximaciones concretas al misterio ontológico

(Trad. J. L. Cañas Fernández). Madrid: Encuentro, 1987.

2004

Obras Completas, Tomo I (Trad. M. Paranjón). Madrid: Biblioteca de Autores Cristianos, 


\section{4.}

. Obras Completas, Tomo II (Trad. M. Paranjón). Madrid: Biblioteca de Autores Cristianos,

\section{Estudios sobre la fillosofía de Gabriel Marcel}

Aguilar, Luis. «La verdad que educa al hombre. Bajo dos miradas filosóficas: María Zambrano y Gabriel Marcel». Teoría y Praxis, n. ${ }^{\circ} 10$ (2007): 90-108.

Cañas, José Luis. Gabriel Marcel: filósofo, dramaturgo y compositor. Madrid: Palabra, 1998.

Davy, Marie-Madeleine. Un filósofo itinerante: Gabriel Marcel (Trad. J. Antonio Pérez Rioja). Madrid: Gredos, 1963.

Gallardo, Antonio. «Apología del cuerpo desde la mirada de Gabriel Marcel». Thémata, n. 33, (2004): 127-134.

Kaufmann, Sebastián. «La metafísica de la existencia humana de Gabriel Marcel». Veritas, n. ${ }^{\circ}$ 28, (2013): 65-84.

Presas, Mario. Biblioteca de pensamiento esencial. G. Marcel. Buenos Aires: Centro Editor de América Latina, 1967.

Urabayen, Julia. «Las sendas del pensamiento hacia el misterio del ser. La filosofía concreta de Gabriel Marcel». Cuadernos de Anuario Filosófico, n. ${ }^{\circ}$ 137, Pamplona: Serie universitaria (2001).

. «Las reflexiones marcelianas sobre la encarnación. Aportes a una comprensión del hombre como ser corporal». Investigaciones Fenomenológicas, vol. monográfico 2: Cuerpo y alteridad (2010), pp. 439-449.

(s. f.). La concepción de Gabriel Marcel acerca de la persona y la dignidad personal. Acceso: 27 de mayo, 2020. http://www.academia.edu/528399/La_concepci\%C3\%B3n _de_Gabriel_Marcel_acerca_de_la_persona_y_la_dignidad_personal

\section{Otros}

Astrada, Carlos. La revolución existencialista. Buenos Aires: Nuevo Destino, 1952.

Abagnano, Nicolás. Introducción al existencialismo. México: Fondo de Cultura Económica, 1980.

Grene, Marjorie. El sentimiento trágico de la existencia. Análisis del existencialismo. Madrid: Aguilar, 1955.

Villegas, Abelardo (Coord.). Las humanidades en el siglo XX, 5 La filosofía. México: Universidad Autónoma de México, 1979. 